\title{
Olefina arinen ekoizpena hondakin plastikoetatik
}

\author{
(Light olefin production from waste plastics)
}

Gartzen Lopez, Maite Artetxe, Maider Amutio, Jon Alvarez, Javier Bilbao, Martin Olazar*

Ingeniaritza Kimiko Saila, Zientzia eta Teknologia Fakultatea

(UPV/EHU)

*martin.olazar@ehu.es

DOI: $10.1387 /$ ekaia.16372

Laburpena: Lan honetan, poliolefinetatik abiatuta, olefinak ekoizteko bi estrategia ezberdin alderatzen dira. Bi kasuetan, lehen etapan, iturri-ohantze konikoko erreaktorean plastikoaren pirolisia egin da. Bigarren etapari dagokionez, bi aukera daude pirolisian sorturiko hegazkorren crackinga egiteko; alde batetik, ohantze finkoan, cracking katalitikoa HZSM-5 zeolita katalizatzaile modura erabiltzea, eta, bestetik, tutu anitzeko erreaktorean tenperatura altuko cracking termikoa erabiltzea.

Hitz gakoak: iturri-ohantze konikoa, pirolisia, olefina arinak, plastikoak, katalizatzailea.

Abstract: In this paper two strategies focused on the production of light olefins from polyolefins are compared. In both cases, the first stage consists in the plastics pyrolysis in a conical spouted bed reactor. With respect to the second stage, two different alternatives have been studied to perform the in-line cracking of the volatiles formed in pyrolysis. In the first alternative, a HZSM-5 catalyst is placed in a fixed bed reactor to perform the catalytic cracking, while in the second one a multitubular reactor is used for the high temperature thermal cracking.

Keywords: spouted bed reactor, pyrolysis, light olefins, plastics, catalyst.

\section{SARRERA}

Plastikozko materialen degradagarritasun baxuarekin lotutako ingurumen-arazoek eta material hauen kontsumo-igoerak beharrezko egin dute 
Gartzen Lopez, Maite Artetxe, Maider Amutio, Jon Alvarez, Javier Bilbao, Martin Olazar

hondakin hauek birziklatzea, zabortegietara isuritako kantitatea gutxitzeko. Beraz, plastikoak balioztatzeko, ezinbestekoa da garatzea eskala handian eraginkorrak diren, ingurumena errespetatzen duten eta ekonomikoki bideragarriak diren teknologiak. Testuinguru honetan, eskala handian hondakin plastikoak balioztatzeko prozesurik egokienetarikotzat jotzen da pirolisia, teknologia egiaztatua, moldaerraza, ingurumena errespetatzen duena eta ekonomikoki bideragarria baita $[1,2]$. Plastikoen pirolisia ezartzeak zenbait abantaila nabarmen ditu; alde batetik, monomeroak berreskuratzea eta autoetarako erregaiak ekoiztea ahalbidetzen du [3], eta, bestetik, gasifikazioprozesuarekin alderatuz, gas eta hegazkor gutxiago sortzen ditu [4].

Eskala handian eta erregimen jarraituan lan egin beharrak teknologia ugariren garapena ekarri du eta erreaktore-mota ezberdin asko erabili dira $[2,4]$. Plastikoen pirolisirako, ohantze fluidizatuko erreaktoreak abantaila ugari ditu; aipagarriena da, bero- eta materia-transferentziarako ahalmen handia izanik, erreaktorean tenperatura konstante iraunaraztea. Teknologia honen nazioarteko erreferentzia Hamburg deituriko prozesua da [5]. Erabilitako beste teknologia batzuen oinarrizko erreaktoreak honako hauek dira: ohantze finkoa, amaigabeko torlojua, plasma eta esferen zirkulaziokoa [1].

\section{a) Iturri-ohantze konikoa b) Ohantze fluidizatua}

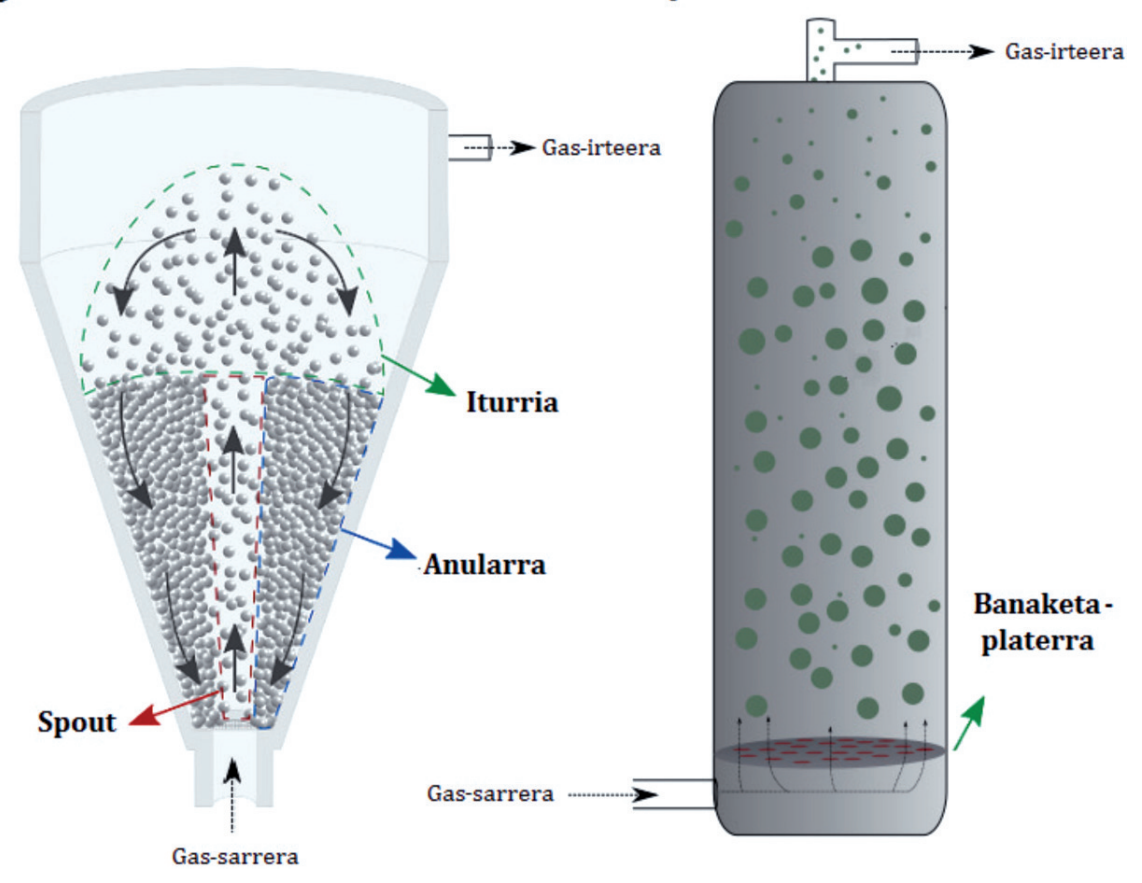

1. irudia. Iturri-ohantze konikoa (a) eta ohantze fluidizatua (b). 
Olefina arinen ekoizpena hondakin plastikoetatik

Iturritu-ohantze konikoan oinarrituriko erreaktoreak eta ohantze fluidizatuan oinarrituak alderatzen badira, zenbait ezaugarri berdintsu dituztela ikusten da, baina defluidizazioa ekiditeko, iturri-ohantze konikoa nabarmenki hobea da [6]. Teknologia hau arrakasta handiz eskalatu da (25 kg/ h-raino) biomasazko hondakinen pirolisirako [7]. 1. irudian erakusten da nolakoak diren iturri-ohantze konikoko eta ohantze fluidizatuko erreaktoreak.

Lan honen helburu nagusia izan da plastiko poliolefinikoen balioztapena (polipropilenoa eta dentsitate altuko eta baxuko polietilenoa, besteak beste) bi etapetan, modu jarraituan egitea, olefina arinak modu hautakorrean lortzeko, bi aukera ezberdin erabiliz. Lehen etapan, plastikoen pirolisi termikoa egin da iturri-ohantze konikoko erreaktorean eta tenperatura baxuan $\left(500{ }^{\circ} \mathrm{C}\right)$. Bigarren etapan (aurrekoarekin lerroan konektatua), hegazkorren (gehienbat ezkoak eta gasoilaren tarteko hidrokarburoak) crackinga (termikoa zein katalitikoa) egin da. Alde batetik, cracking termikoa, tenperatura altuan eta tutu anitzeko erreaktorean, egin da, egoitza-denbora laburretan, olefina arinen etekina maximizatzeko eta hidrokarburo aromatikoen eta metanoaren moduko albo-produktuen eraketa saihesteko. Bestalde, aukera katalitikoan, ohantze finkoa eta katalizatzaile gisa HZSM-5 zeolita erabili dira, olefina arinak ekoizteko, ezaugarri egokiak dituelako $[8,9]$. 2. irudian erakusten da proposatutako bi aukeren eskema.

a)

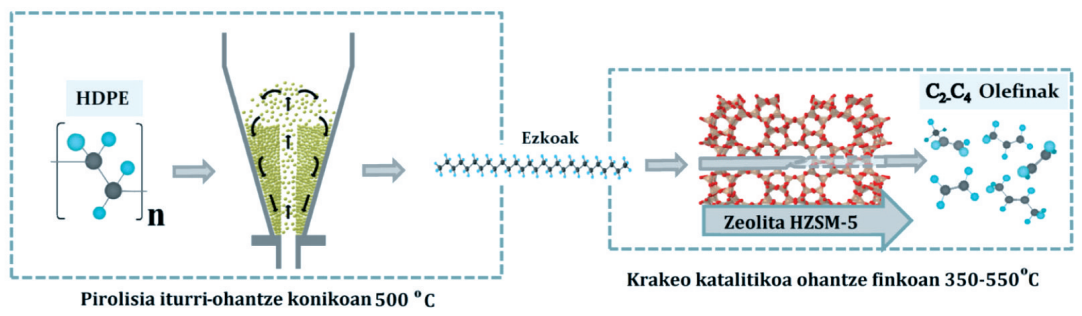

b)

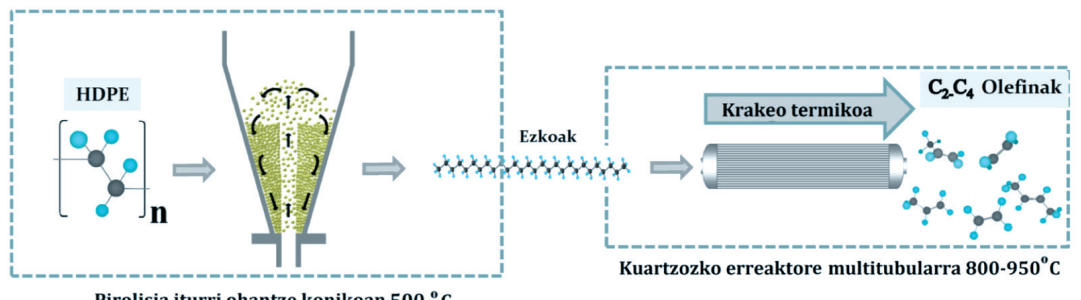

2. irudia. HDPEtik abiatuta, cracking katalitikoaren (a) eta termikoaren (b) bitartez, olefina arinak lortzeko eskemak. 
Gartzen Lopez, Maite Artetxe, Maider Amutio, Jon Alvarez, Javier Bilbao, Martin Olazar

\section{ATAL ESPERIMENTALA}

Ikerketa honetan erabili den plastikoa Dow Chemical-ek (Tarragona) hornitutako dentsitate altuko polietilenoa (HDPE) izan da. Haren ezaugarri nagusiak honako hauek dira: $46200 \mathrm{~g} /$ mol-eko pisu molekularra, $930 \mathrm{~kg} /$ $\mathrm{m}^{3}$-ko dentsitatea, 2.89-ko polidispertsibitatea eta $43 \mathrm{MJ} / \mathrm{kg}$-ko goi beropotentzia. Plastiko poliolefiniko guztien adierazgarri modura HDPEa aukeratu da.

Erabilitako katalizatzailearen oinarria HZSM-5 zeolita izan da, silize/ alumina $\left(\mathrm{SiO}_{2} / \mathrm{Al}_{2} \mathrm{O}_{3}\right)$ mol-proportzioa 30 izan da eta hornitzailea Zeolyst International (Kansas, AEB) izan da. HZSM-5 zeolita aukeratu da, olefina arinak lortzeko barne-egitura eta azidotasuna egokiak dituelako [8, 9]. Zeolita amonio forman hornitua izan denez, erabili aurretik, kiskali egin da, amoniakoa kentzeko. Kiskaltzea $575{ }^{\circ} \mathrm{C}$-an egin da, katalizatzailea egonkorragoa egiteko. HZSM-5 zeolita (\% 25), bentonita (\%30) eta $\mathrm{Al}_{2} \mathrm{O}_{3}$-a (\% 45) estruzio hezearen bidez aglomeratu dira; hau da, zeolita (fase aktiboa) bentonirarekin eta aluminarekin nahastu ondoren, estruzioaren bidez, nahi izan den forma eman zaio katalizatzaileari. Gainera, prosezu honek katalizatzailearen erresistentzia mekanikoa hobetzen du eta katalizatzailea bentonitak eta aluminak dituzten meso eta makroporoez hornitzen da, kokearen aitzindarien difusioa errazteko eta mikroporoen blokeoa arintzeko. Lehortu ostean, katalizatzailea bahetu da eta 1 eta $2 \mathrm{~mm}$ tarteko partikula-diametroa aukeratu da ohantze finkoko erreaktorean erabiltzeko. Bukatzeko, 2 orduz kiskali da.

Lerroan konektaturiko bi erreaktore dituen laborategiko instalazioan egin dira pirolisi-cracking saiakuntzak. Lehen erreaktorea $500{ }^{\circ} \mathrm{C}$-ko tenperaturan dagoen iturri-ohantze konikoko erreaktorea da, eta $50 \mathrm{~g}$ harea ditu. Cracking katalitikoa aztertu den kasuan, bigarren erreaktore moduan ohantze finkoa erabili da, eta $8 \mathrm{~g}$ katalizatzaile erabili dira saiakuntza bakoitzean. Etapa honetan, tenperaturak 350-550 ${ }^{\circ} \mathrm{C}$-ko tartean produktuen etekinean duen eragina aztertu da. Cracking termikoa egin denean, bigarren erreaktore moduan kuartzozko hodiz (1 mm-ko diametrokoak) beteriko erreaktorea erabili da, eta $800-950{ }^{\circ} \mathrm{C}$-ko tartean aztertu da tenperaturak produktuen etekinean duen eragina.

Plastikoa modu jarraituan elikatuz ( $1 \mathrm{~g} / \mathrm{min})$ egin dira saiakuntzak, eta nitrogenoa erabili da fluidizazio-eragile gisa. Lorturiko produktu hegazkorrak lerroan aztertu dira, kromatografia (Varian 3900) eta microkromatografia (Varian 4900) erabilita. Masa-espektrometroa duen kromatografoaren bidez aztertu da kondentsadorean eta iragazkietan lorturiko frakzio likidoa (Shimadzu QP2010S). 
Olefina arinen ekoizpena hondakin plastikoetatik

\section{PIROLISI TERMIKOA LEHEN ETAPAN}

Lehendabizi, pirolisi termikoko etapan (lehen etapan) lortu den hegazkorren emaria aztertu da, korronte hauxe elikatu baita bigarren etapara, cracking termikoa edo katalitikoa egiteko.

Iturri-ohantze konikoko erreaktorearen ezaugarri onak direla eta, plastikoen pirolisi termikoa tenperatura baxuan $\left(500{ }^{\circ} \mathrm{C}\right)$ egin daiteke defluidizazio arazorik gabe. Horrela, lortzen den korrontea ezko- $\left(\mathrm{C}_{20}+\right)$ eta diesel- $\left(\mathrm{C}_{12}-\mathrm{C}_{20}\right)$ frakzioez osatua dago batez ere, eta bien arteko etekina \% 90 baino altuagoa da. Horrez gain, krakeatzeko zailak diren konposatuen etekina, hots, aromatikoena (\% 0.28 masan) eta metanoarena (\% 0.03 masan), oso baxua da. Gainera, cracking termikoa edo katalitikoa egiteko emari egokia lortzeaz gain, prozesua modu jarraituan egiteak kontzentrazio konstantea duen emaria lortzea ahalbidetzen du, eta hori nahitaezkoa da bigarren etapako lan-baldintzak egoki aztertzeko.

Aipatzekoa da iturri-ohantze konikoko erreaktorea oso teknologia egokia dela, HDPEaren pirolisiaren bidez, ezkoak lortzeko. Alde batetik, erreaktore honetan solidoak duen mugimendu zikliko eta indartsuak minimizatzen ditu plastikoen pirolisiaren aurreko etapa fisikoak sortutako arazoak. Aurreko etapa fisiko horiek, besteak beste, plastikoaren urtzea eta plastiko urtuak partikula solidoak estaltzea dira. Etapa fisiko hauen arazoak minimizatzean, beste erreaktoreetan, tenperatura baxuan, gertatu ohi diren defluidizazio-arazoak ekiditen dira [6]. Bestalde, iturriohantze konikoaren ezaugarri diren bero- eta materia-transferentziaren abiadura handiek, baita tenperatura baxuan ere $\left(500{ }^{\circ} \mathrm{C}\right)$, ahalbidetzen dute ezkoak sortzeko partikula solidoen gainean era uniformean ezarritako plastiko urtuaren hegazkortze azkarra. Horrez gain, sorturiko hegazkorrek erreaktorean duten egoitza-denbora baxuak bigarren mailako erreakzioak minimizatzen ditu, eta, batez ere, ezkoz osaturiko emaria lortzen da.

\section{PIROLISIA ETA CRACKING KATALITIKOA BI ETAPAKO PROZESUAN}

Pirolisi-etapan sorturiko hegazkorrak tenperatura altuan irteten dira, $300{ }^{\circ} \mathrm{C}$-an gutxi gorabehera, eta ohantze finkoko erreaktorera elikatzen dira bertan, HZSM-5 zeolita erabiliz, cracking katalitikoa egin ahal izateko. Lorturiko produktuak 5 lump edo taldetan banatu dira: olefina arinak $\left(\mathrm{C}_{2}-\mathrm{C}_{4}\right)$, alkano arinak $\left(\mathrm{C}_{1}-\mathrm{C}_{4}\right), \mathrm{C}_{5}-\mathrm{C}_{11}$ aromatikoak, $\mathrm{C}_{5}$ - $\mathrm{C}_{11}$ ez-aromatikoak eta $\mathrm{C}_{12}{ }^{+}$hidrokarburoak. 3. irudian erakusten dira tenperatura ezberdinetan lorturiko frakzioen etekinak (3a Irudia) eta gas- frakzioa osatzen duten konposatuen etekinak ( $3 \mathrm{~b}$. irudia). 
Gartzen Lopez, Maite Artetxe, Maider Amutio, Jon Alvarez, Javier Bilbao, Martin Olazar

Lorturiko emaitzek argi erakusten dute erabilitako katalizatzaileak (HZSM-5 zeolita) duen aktibitatea ezkoak hidrokarburo arinetan eraldatzeko, ezkoen etekina $\left(\mathrm{C}_{12}{ }^{+}\right.$frakzioa barne) ia mespretxagarria baita aztertu den tenperatura-tartean. Horrez gain, argi dago katalizatzaileak duen ahalmena olefina arinak era hautakorrean lortzeko.

Ohantze katalitikoan tenperatura igotzeak olefina arinen etekina handiagotzea dakar, \% 31.5etik $\left(350{ }^{\circ} \mathrm{C}\right.$-an $) \%$ 63ra $\left(550{ }^{\circ} \mathrm{C}\right.$-an $)$. Era berean, tenperaturaren igoerak aromatikoen frakzioaren etekina handitzen du: $550{ }^{\circ} \mathrm{C}$-an, \% 12.5eko etekina lortzen da. Bi frakzio hauen igoeraren ondorioz, ohantze katalitikoko tenperatura igotzeak $\mathrm{C}_{5}-\mathrm{C}_{11}$ frakzio ez-aromatikoaren etekinaren jaistea dakar, \% 47tik $\left(350{ }^{\circ} \mathrm{C}\right.$-an $) \% 11.7 \mathrm{ra}\left(550{ }^{\circ} \mathrm{C}\right.$-an $)$. Alkano arinetan eta $\mathrm{C}_{12}{ }^{+}$frakzioan tenperaturak duen eragina txikiagoa dela ikus daiteke. Aztertu den tenperatura-tartean alkano arinen etekinak $450{ }^{\circ} \mathrm{C}$-an $\left(\%\right.$ 12.6) du maximoa. $\mathrm{C}_{12}{ }^{+}$frakzioari dagokionez, $350{ }^{\circ} \mathrm{C}$-an $\%$ 10eko etekina izatetik $450{ }^{\circ} \mathrm{C}$-an \% 5.7ko etekina izatera pasatzen da. Hala ere, $450-550{ }^{\circ} \mathrm{C}$ tartean esan daiteke tenperaturak frakzio honen etekinean eraginik ez duela.
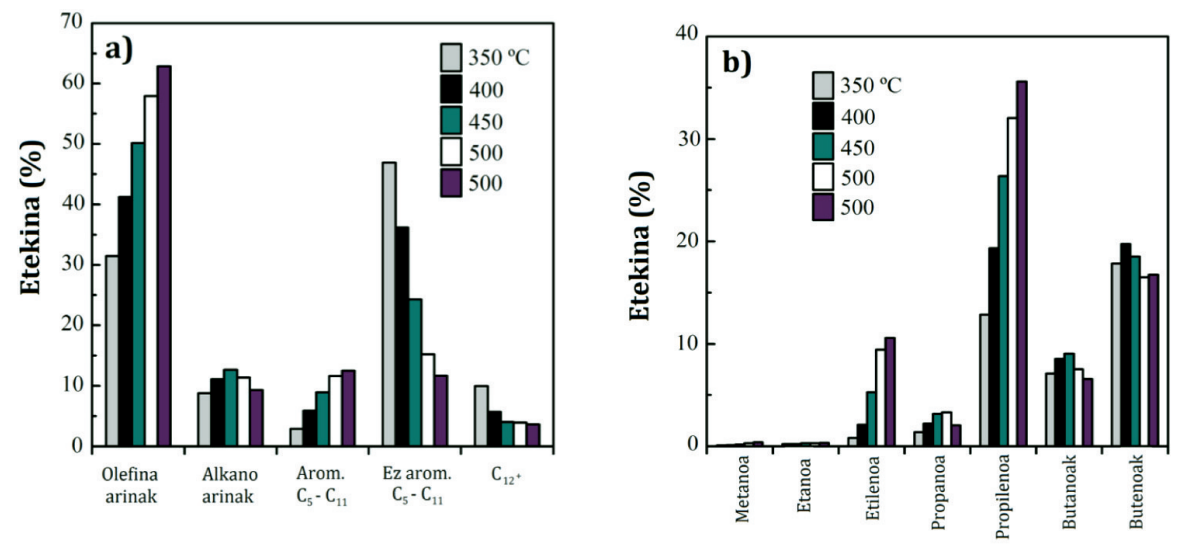

3. irudia. Pirolisia eta craking katalitiko bi etapako prozesuan lortutako frakizoen etekinak (a) eta gasa osatzen duten konposatuen etekinak (b) tenperatura ezberdinetan.

3b. irudian gas-frakzioko $\left(\mathrm{C}_{1}-\mathrm{C}_{4}\right)$ konposatuetan tenperaturak duen eragina ikus daiteke. Aipagarria da tenperatura $350{ }^{\circ} \mathrm{C}$-tik $550{ }^{\circ} \mathrm{C}$-ra igotzean, propilenoaren etekina igotzea; izan ere, produktu hau nagusia da eta $\%$ 35.6ko etekina du. Horrez gain, tenperatura igotzean, etilenoaren etekina ere handitzen da, $\%$ 0.8tik $\left(350{ }^{\circ} \mathrm{C}\right.$-an $) \% 10.6 \mathrm{ra}\left(550{ }^{\circ} \mathrm{C}\right.$-an $)$. Butenoei dagokienez, tenperatura baxuan $\left(350{ }^{\circ} \mathrm{C}\right.$-an $)$ gas-frakzioko produktu nagusiak dira eta nahiz eta etekin maximoa $400{ }^{\circ} \mathrm{C}$-an izan (\% 19.7), tenperaturak frakzio honen etekinean eragin handirik ez duela esan daiteke. 
Olefina arinen ekoizpena hondakin plastikoetatik

\section{PIROLISIA ETA CRACKING TERMIKOA BI ETAPAKO PROZESUAN}

Lehenago azaldutako pirolisia eta cracking katalitikoa estrategiarekin erkatuz, pirolisia eta cracking termikoa dituen bi etapako prozesua aukera interesgarria da, HDPEtik abiatuz, olefina arinak ekoizteko. Erabilitako bi erreaktoreek (iturri-ohantze konikoa eta tutu anitzeko erreaktorea) dituzten ezaugarri onak sustatu egiten dira, seriean konektatzen direnean. Bigarren erreaktoreko egoitza-denbora baxuaz eta tenperatura altuaz gain, lehen erreaktoretik datorren emariaren konposizio homogeneoak eta hegazkorren diluzio altuak eragina dute olefina arinen ekoizpen hautakorrean. 4. irudian ageri dira tenperatura ezberdinetan $\left(800-950{ }^{\circ} \mathrm{C}\right)$ lorturiko frakzio ezberdinen etekinak (4a Irudia) eta gas-frakzioa osatzen duten konposatuenak (4b. irudia).

Ikus daitekeen moduan, bigarren erreaktorean erabiltzen den tenperaturak eragin handia du lorturiko produktuen banaketan. Horrela, ikus daiteke olefina arinen etekin maximoa $850-900{ }^{\circ} \mathrm{C}$ tartean lortzen dela eta etilenoaren, propilenoaren eta butenoen etekin indibidualak \% 39.8, \% 19.2 eta \% 17.2 direla, hurrenez hurren. Alde batetik, $900{ }^{\circ} \mathrm{C}$-tik behera lan egiten denean, tenperaturaren igoerak $\mathrm{C}_{12}{ }^{+}$eta $\mathrm{C}_{5}-\mathrm{C}_{11}$ frakzioen crackinga eragiten du eta olefina arinen etekinak gora egiten du. Horrez gain, tenperaturaren igoerak bigarren mailako erreakzioak diren hidrogeno-transferentzia eta kondentsazioa bultzatzen ditu eta alkano arinen eta eraztun bakarreko aromatikoen etekina handiagotzen du. Bestalde, $900{ }^{\circ} \mathrm{C}$-tik gora lan egitean, tenperaturaren igoerak eraztun bakarreko aromatiko eta poliaromatikoen eratzea dakar eta, ondorioz, olefina arinen etekinaren beherakada azkarra.
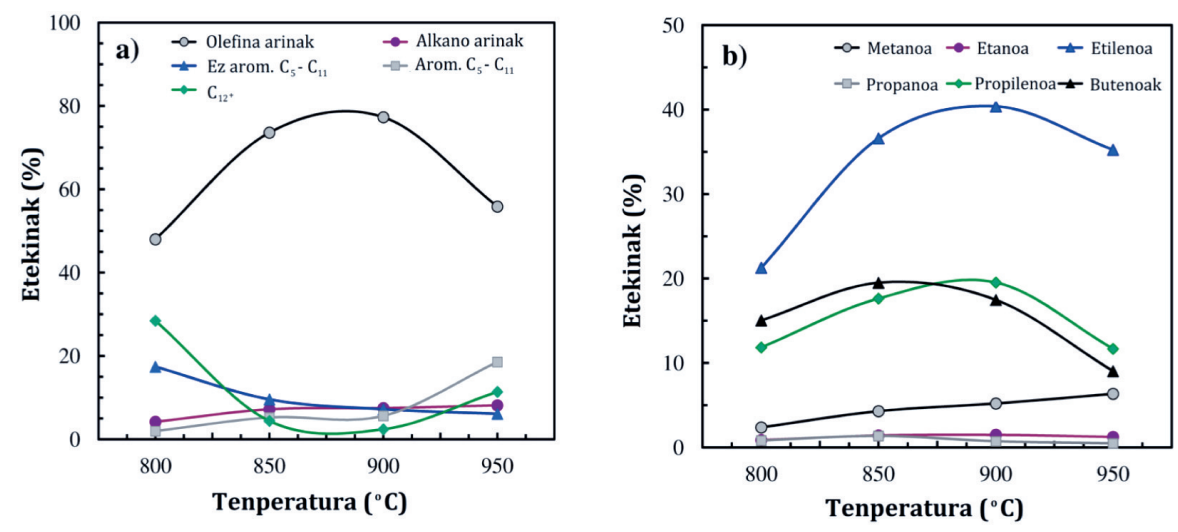

4. irudia. Pirolisia eta craking termikoa bi etapako prozesuan eginez lortutako osagai-frakzioen etekinak (a) eta gasa osatzen duten konposatuen etekinak (b) tenperatura ezberdinetan. 
Gartzen Lopez, Maite Artetxe, Maider Amutio, Jon Alvarez, Javier Bilbao, Martin Olazar

\section{ONDORIOAK}

Pirolisi-cracking katalitikoan eta pirolisi-cracking termikoan oinarritutako estrategiek olefina arinen etekinean desberdintasunak sortarazten dituzte, hots, lehenengoak, \% 62ko etekina $550{ }^{\circ} \mathrm{C}$-an, eta bigarrenak, $\%$ 77ko etekina $850-900{ }^{\circ} \mathrm{C}$-an. Hala ere, bi estrategien arteko ezberdintasunik nabarmenena hiru olefinen arteko hautakortasunari dagokio, pirolisi-cracking katalitikoak propilenoa era hautakorrean (\% 36ko etekina) eta pirolisi-cracking termikoak etilenoa era hautakorrean (\% 40ko etekina) ematen baitute. Eskala handiko prozesuaren bideragarritasunari dagokionez, operazio-kostuetan desberdintasun handia dago, cracking katalitikoan katalizatzailea erabili behar baita eta cracking termikoan $400{ }^{\circ} \mathrm{C}$ baino tenperatura altuagoa erabili behar baita.

\section{BIBLIOGRAFIA}

[1] BUTLER, E., DEVLIN, G., MCDONNELL, K. 2011. «Waste Polyolefins to Liquid Fuels via Pyrolysis: Review of Commercial State-of-the-Art and Recent Laboratory Research». Waste Biomass Valorization, 2, 227-255.

[2] AL-SALEM, S.M., LETTIERI, P., BAEYENS, J. 2009. «Recycling and recovery routes of plastic solid waste (PSW): A review». Waste Management, 29, 2625-2643.

[3] WONG, S.L., NGADI, N., ABDULLAH, T.A.T., INUWA, I.M. 2015. «Current state and future prospects of plastic waste as source of fuel: A review». Renewable and Sustainable Energy Reviews, 50, 1167-1180.

[4] AGUADO, J., SERRANO, D.P., ESCOLA, J.M. 2008. «Fuels from Waste Plastics by Thermal and Catalytic Processes: A Review». Indusrial \& Engineering Chemistry Research, 47, 7982-7992.

[5] KAMINSKY, W., PREDEL, M., SADIKI, A. 2004. «Feedstock recycling of polymers by pyrolysis in a fluidised bed». Polymer Degradation and Stability, 85, 1045-1050.

[6] ElORDi, G., OlAZAR, M., LOPEZ, G., ARTETXE, M., BilbAO, J. 2011. «Product Yields and Compositions in the Continuous Pyrolysis of High-Density Polyethylene in a Conical Spouted Bed Reactor». Indusrial \& Engineering Chemistry Research, 50, 6650-6659.

[7] FERNANDEZ-AKARREGI, A.R., MAKIBAR, J., LOPEZ, G., AMUTIO, M., OLAZAR, M. 2013. «Design and operation of a conical spouted bed reactor pilot plant $(25 \mathrm{~kg} / \mathrm{h})$ for biomass fast pyrolysis». Fuel Processing and Technology, 112, 48-56.

[8] LIN, Y.H., YANG, M.H. 2008. «Tertiary recycling of polyethylene waste by fluidised-bed reactions in the presence of various cracking catalysts». Journal of Analytical and Applied Pyrolysis, 83, 101-109.

[9] MASTRAL, J.F., BERRUECO, C., GEA, M., CEAMANOS, J. 2006. «Catalytic degradation of high density polyethylene over nanocrystalline HZSM-5 zeolite». Polymer Degradation and Stability, 91, 3330-3338. 